\title{
The Research on Influencing Factors of Medical Logistics Cost Based on ISM Model
}

\author{
Yunkai Zhai ${ }^{1,2,3}$ and Yingchao $\mathrm{Li}^{1{ }^{1,}}$ \\ ${ }^{1}$ Management Engineering School, Zhengzhou University, Zhengzhou, People's Republic of China \\ ${ }^{2}$ Henan Engineering Research Center of Digital Medicine, Zhengzhou, People's Republic of China \\ ${ }^{3}$ The first Affiliate Hospital, Zhengzhou University, Zhengzhou, People's Republic of China \\ Corresponding Email: 995680589@qq.com
}

\begin{abstract}
The reason why medical logistics cost remains high is a system problem, this paper analyzes the system through the ISM model. The result presents that medical logistics cost factors have four levels of relationship, primary factor is the national policies, secondary factors are the talent construction and pharmaceutical enterprise scale, Intermediate factors are medical information management system and inventory cost, the key factors are transportation cost and distribution center location. Finally, according to the four levels of relationship, this paper put forward specific suggestions to reduce logistics cost.
\end{abstract}

\section{Introduction}

With the progress of science and application of online intelligence platform, social logistics cost gradually decreases, because of medical logistics has the characteristic of highly professional, high degree of complexity, strong timeliness and high security, the medical logistics cost still remains high. There is a lot of researches focus on reducing medical logistics cost, however, most of them are one-sided, the papers just analysis a factor and then put forward countermeasures to reduce medical logistics cost. The effect of this kind of research method is limited to reduce the cost of medical logistics.

Through reading literature, we find that the papers about reducing medical logistics cost focus on constructing online information sharing platform, improving the efficiency and establishing third party pharmaceutical logistics enterprises. However, there is no research on the relationships among the factors. Naturally, there is no research to study the primary and secondary relation between factors of medical logistics cost. The main documents of reducing the medicine logistics cost are as follows.

Lin Xiaoxia [1](2014) points out the domestic medicine distribution centers have the problem of operation is not standardized and the degree of material flow is low; she believes that medical logistics distribution system can promote the distribution center's operation efficiency and improve the level of logistics, so as to reduce the medicine logistics cost. Zhang Luyue [2](2012) points out the composition of distribution costs (including the cost of distribution transport and sorting) and the influencing factors of distribution cost (market competition factors, distribution management factors and so on), she advocates to reduce the logistics cost by consolidation strategy and delay strategy. Wang Chuanlei [3](2015) points out the green distribution system of medical logistics. Based on the characteristics of the medical logistics, combining the operating system, recovery system and information system, Constructing the green distribution system of medical logistics, so as to reduce the cost of logistics, and ensure the development of medical logistics healthy and orderly. Wei Hua [4](2015) points out the construction of medical logistics information sharing platform has the positive effect to reduce the cost of medical logistics, and he proposes a modern medical logistics sharing information platform based on automatic recognition technology. These documents analysis and put forward recommendations just from one simple perspective.

This paper identifies the important factors through literature research and expert consultation and analysis the medical logistics cost factor from primary to secondary, then puts forward effective and reasonable suggestions.

\section{The influencing factors of medical logistics cost}

Through the analysis of the literature and Delphi method, this paper identify 7 main factors as follows.

\subsection{Location of medical distribution center}


The rationality of distribution center location has a direct impact on other factors in medical logistics, so it should be reasonable as far as possible. The location of medical distribution center has qualitative and quantitative method. Qualitative method has the analytic hierarchy process and the fuzzy clustering method. Quantitative methods include heuristic algorithm, gravity method, Baumol-Wolfe method and mixed 0-1 integer programming model combination method, simulation algorithm and so on.

\subsection{Medical information management system}

With the development and application of big data and other network technology, online medical information platform came into being, the influence of online medicine information platform on medical logistics cost is mainly reflected in the following two points.

\subsubsection{Direct impact}

The online medical information platform can integrate the medical chain enterprises with the requirements of hospital, so that the information can be shared on the platform, the drug demand can get the information about the supply through the platform so as to meet their needs. by this way, they can reduce the cost of purchase time and transportation costs, at the same time, After receiving the order, the supplier can classify orders (drug types, distribution area, time, etc.), improving the efficiency of distribution.

\subsubsection{Indirect effect}

The online medical information platform not only open for the medical chain enterprises and hospitals but also open to individuals, medical chain enterprises and hospitals have the ability to identify the authenticity of the drugs, however, it is difficult to identify the authenticity for the individual. Especially in the last few years, the report of the poison capsule event which lead to bad impression to the people, worse more, people may not buy drugs through online medical information platform, this may cause warehousing and logistics system can not play its due value and increase the cost of medical logistics indirectly.

\subsection{Inventory cost}

The effect of inventory is to adjust the balance between supply and demand, the high inventory increase the management costs and storage costs, the low inventory lead to short supply risk. Due to the storage of the medical products require certain temperature, humidity and other conditions, which leads to the high cost of storage.

\subsection{The size of medical logistics enterprise}

According to the 2013-2017 the research of China medical logistics industry and analysis report of investment strategy planning, there are 13000 medical logistics enterprises in China, large enterprises accounted for only $20 \%$, present the state of Many, small, scattered, chaotic; medical logistics enterprises in the top four accounts for only about $30 \%$ of the medical logistics market share, by contrast, the U.S. top three medical logistics enterprises reached more than $95 \%$ in the medical market share. If the size of medical logistics enterprises is too small, the standard, operation mode and distribution efficiency will affect the whole medical logistics cost.

\subsection{Transportation cost}

According to statistics, transport costs accounted for $40 \%$ of the overall logistics costs, such a high proportion makes the medical logistics enterprises recognize importance of reducing the transportation costs. However, due to the characteristics of medical products, in the process of transportation must keep the physical condition, such as temperature, humidity, etc. To meet the requirements, special transport facilities are required and transport personnel need professional operating skills.

\subsection{Talents construction}

Medical logistics is different from the general logistics, it is more professional and stronger, to achieve a certain standard, it requires the participation of professional talents who have professional skills and medical knowledge.

\subsection{National policy}

The national policy is also the influencing factor of medical logistics cost, because the policy can determine development of medical logistics, such as guiding the construction of the distribution center and encouraging the 
development of large medical logistics enterprises etc.. If the country does not pay attention to the medical logistics, then the development of medical enterprises will be in disarray, a series of problems may appear. For example, 570 million illegal vaccine case happened in 2016, if the Illegal vaccine can be seized in logistics chain, a series of vicious consequences can be avoided. Therefore, national policy-making, not only can reduce the cost of medical logistics but also ensure the medical market be more stable and healthy .

\section{Systematic analysis of the influencing factors of medical logistics cost based on ISM model}

Interpretive structure model [5,6](ISM model) is presented by American professor Warfield in 1973, the model based on qualitative analysis, its function is decomposing a complex system into subsystems (elements), then hierarchical processing of these elements, so as to show the relationship between the elements.

There are connections between the different influence factors of medical logistics cost, the connections constitute a system. Analyzing the system through ISM model can point out the way to reduce medical logistics cost.

\subsection{Draw directed graph}

Through the analysis of the literature and Delphi method, the relationship between the various factors as shown in Figure 1.

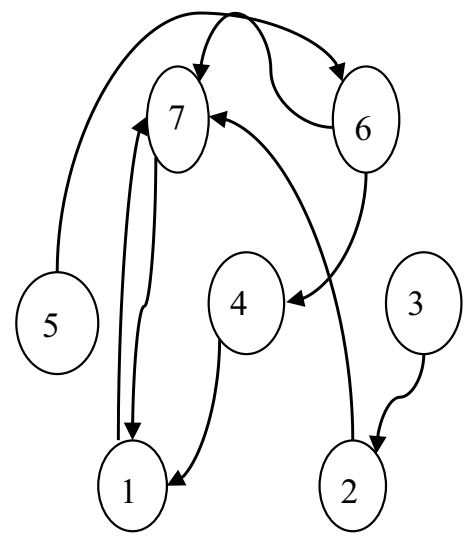

Fig. 1. the relationship between the various factors.

In Figure 1, 1 indicates the location of medical distribution center, 2 indicates the medical information management system, 3 indicates talents construction, 4 indicates inventory cost, 5 indicates the national policy, 6 indicates the size of medical logistics enterprise, 7 indicates the transportation cost.

\subsection{Draw the relationship table}

Based on the transfer of the relationship between the two elements, inferring the binary relation of the elements, and according to the directed graph, drawing the relationship table as shown in table1.

Table 1. The relationship table.

\begin{tabular}{|c|c|c|c|c|c|}
\hline $\mathrm{X}$ & (A) & & & A & (A) \\
\hline $\mathrm{V}$ & & & & $\mathrm{A}$ & 2 \\
\hline & & & & 3 & \\
\hline $\mathrm{V}$ & $\mathrm{A}$ & (A) & 4 & & \\
\hline (V) & $\mathrm{V}$ & 5 & & & \\
\hline $\mathrm{V}$ & 6 & & & & \\
\hline
\end{tabular}

\subsection{Write out the reachable matrix}

Write out the reachable matrix according to the relationship table. 
$\mathbf{M}=\begin{array}{llllllll}1 & 2 & 3 & 4 & 5 & 6 & 7 \\ 1 \\ 2 \\ 3 \\ 4 \\ 5 \\ 6 \\ 7\end{array}\left(\begin{array}{lllllll}1 & 1 & 0 & 0 & 0 & 0 & 1 \\ 0 & 1 & 1 & 0 & 0 & 0 & 0 \\ 1 & 0 & 0 & 1 & 0 & 0 & 1 \\ 0 & 0 & 0 & 1 & 1 & 1 & 1 \\ 1 & 0 & 0 & 1 & 0 & 1 & 1 \\ 1 & 0 & 0 & 0 & 0 & 0 & 1\end{array}\right)$

Write out the reduced matrix according to the reachable matrix:

$$
M^{\prime}=\begin{array}{r}
1 \\
2 \\
3 \\
4 \\
5 \\
6
\end{array}\left(\begin{array}{llllll}
1 & 0 & 0 & 0 & 0 & 0 \\
1 & 1 & 0 & 0 & 0 & 0 \\
0 & 1 & 1 & 0 & 0 & 0 \\
1 & 0 & 0 & 1 & 0 & 0 \\
0 & 0 & 0 & 1 & 1 & 1 \\
1 & 0 & 0 & 1 & 0 & 1
\end{array}\right)
$$

Hierarchical processing:

$$
\mathrm{M}^{\prime}(1)=\begin{array}{l|l|lllll}
1 \\
4 \\
2 \\
3
\end{array}\left(\begin{array}{llllllll}
{[1} & 0 & 0 & 0 & 0 & 0 \\
& 1 & 1 & 0 & 0 & 0 & 1 \\
1 & 0 & 1 & 0 & 0 & 0 \\
5 & 0 & 0 & 1 & 1 & 0 & 0 \\
5 & 1 & 1 & 0 & 0 & 1 & 0 \\
0 & 1 & 0 & 0 & 1 & 1
\end{array}\right)
$$

After the Hierarchical processing, the elements are divided into four layers, the first layer is the factor 1, the second layer are factor 2 and factor 4 , the third layer are factor 3 and factor 6 , the forth layer is factor 5 . Drawing the multi class directed graph based on hierarchical, as shown in Figure 2.

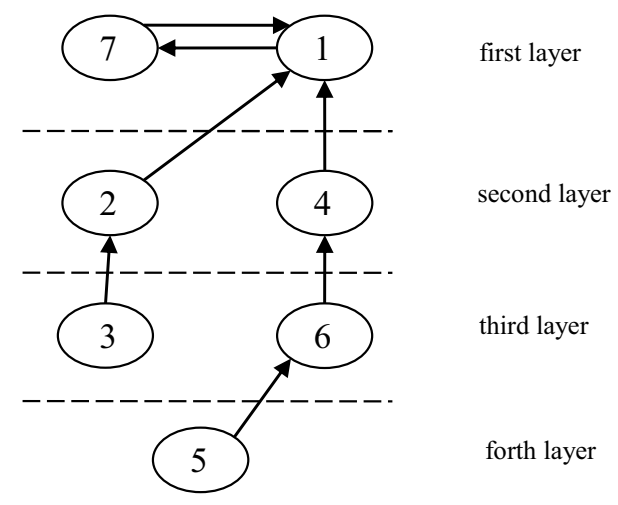

Fig .2. The multi class directed graph.

\subsection{ISM model of influencing factors of medical logistics cost}

According to the multi class directed graph, getting the ISM model of the influencing factors of the medical logistics cost as shown in Figure 3. 


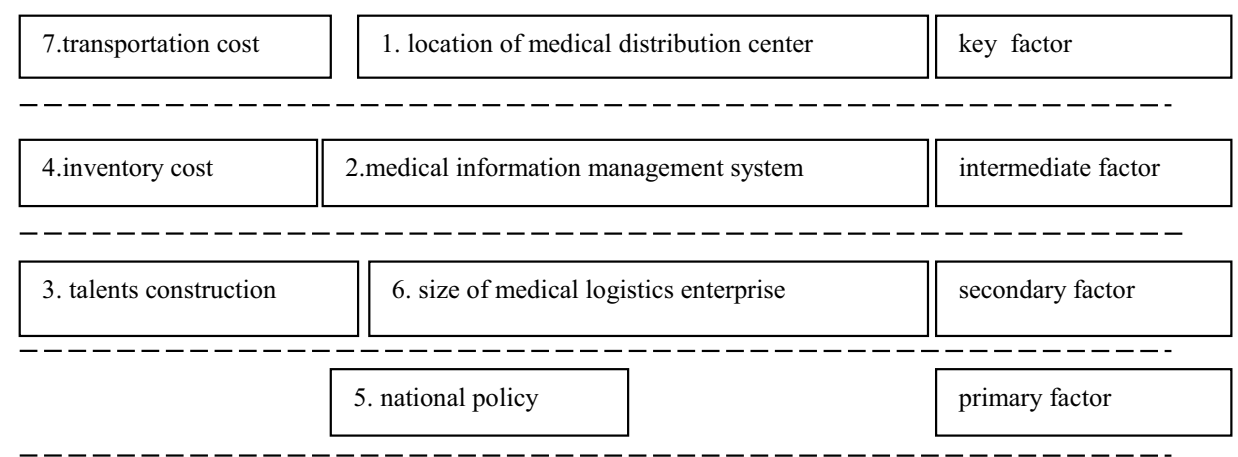

Fig. 3. ISM model of the influencing factors of the medical logistics cost.

According to Figure 3, medical logistics cost factors have four levels of relationship, primary factor is the national policies, secondary factors are the talent construction and pharmaceutical enterprise scale, Intermediate factors are medical information management system and inventory cost, the key factors are transportation cost and distribution center location.

\section{The measures to reduce the medical logistics cost}

\subsection{Policy-making}

The characteristics of medical logistics determine that it is different from the general logistics, in order to speed up the development of medical logistics, and reduce the medical logistics cost effectively, it is necessary to formulate a series of policies to reduce the medical logistics cost.

First, through administrative, legal and economic means to integrate medical market and optimize the allocation of resources, then promoting the merger of medical logistics enterprises, improving the share of large medical logistics enterprises in the medical market, so that laying a solid foundation for the standardization of medical logistics market. Secondly, formulating relevant policies to develop talents who good at medical logistics, what's more, it is necessary to put the talent construction on the strategic level.

The formulation of the national policy should not limited to these two aspects, it should be planned in overall picture, and perform it from the national level, The future of the medical logistics market is bound to have a new look, the medical logistics costs will also be controlled and gradually reduced.

\subsection{Strengthen the construction of talent and expand the scale of pharmaceutical logistics enterprises}

\subsubsection{Strengthen the construction of talent}

Talent is the basis for the development of any industry, leaving the talent building and talent supplement, the industry is like the air loft. The demand for talents of medical logistics is more unique, it requires of medical logistics staff is not only proficient in logistics knowledge but also good at medical knowledge, Inter-disciplinary talents are necessary to adapt to the development of medical logistics industry.

First of all, college should set up a courses that students can learn about logistics and medical, through this way , Cultivating students' comprehensive ability. secondly, promoting the students to practice in medical enterprises actively, to cultivate the student's practical ability so that laying a good foundation for joining the medical logistics industry.

\subsubsection{Expand the scale of pharmaceutical logistics enterprises}

In view of the present situation of the medical logistics enterprises in our country, which is many, small, scattered and chaotic, small medical logistics enterprises should be set up to form large medical logistics enterprises, or large medical logistics enterprises merge small medical logistics enterprises mergers. In this way, the present situation of the medical logistics enterprises can be solved, and medical logistics resources can be integrated. What's more, the medical distribution, transportation and storage can achieve scale and more manageable.

\subsection{Promote the construction of medical information management system and reduce the Inventory} costs 


\subsubsection{Promote the construction of medical information management system}

The development of the Internet and big data provides good opportunity and technical support for the construction of medical information platform. Based on Internet and big data, constructing medical information platform that matches the medical characteristics, demand-side and supply-side can get the information through medical information platform. The medical information management system can also get rid of the information communication barriers and realize share of information, so as to achieve the goal of saving procurement time, improving the distribution efficiency, and reducing the transportation cost.

\subsubsection{Reduce inventory cost}

If the inventory cost of medical company is too high, then the cost will be added to the transportation and distribution, therefore reducing the cost of medical enterprises is particularly important. Due to the special requirements of the medicine storage, such as a certain temperature and humidity conditions, then it would spend much money to build warehouse, which result in high storage costs, so it requires the implementation of effective and reasonable inventory management methods to reduce the cost of management and warehousing. For example, VMI (Vendor Managed Inventory), CPFR (Collaborative Planning Forecasting and replenishment), RMI (Joint Inventory Management), etc., these method can help to reduce inventory cost, we can also combine these methods to create new way to reduce inventory cost.

\subsection{Reduce the transportation cost and optimize distribution center allocation}

\subsubsection{Reduce transport costs}

The reason why transport cost is so high is that too many transit times, distribution path is unreasonable, the vehicle load, therefore, we can reduce the cost of transport starting from the three aspects. First of all, Through the medical information platform, medical logistics enterprises can Load and distribute medicine uniformly. Secondly, at the end of the distribution stage, it is necessary to carry out a reasonable transport path planning, and ensure that there is no return in the process of transportation and distribution, so that improving the efficiency of transport. Finally, after the distribution, medical logistics enterprises should look for goods that suitable for function of vehicle, through this way, the cost due to no-load can be reduced.

\subsubsection{Optimize distribution center allocation}

Distribution center allocation is related to the distribution efficiency, how to measure distribution center allocation is essential to reduce the cost of medicine logistics. The allocation is an important and complex system engineering. Due to the characteristics of medical logistics, the medical logistics distribution center allocation is more complex and much more factors to consider. For example, Drug consumption in the region, traffic conditions, etc. So it is important to take all factors into account and never build the medical distribution center blindly that does not meet the needs of the region. Otherwise, the large scale will lead to high cost of construction, resulting in waste of resources, if the size is too small ,then it can't meet the needs of distribution.

\section{Summary}

This paper analyzes the medical logistics cost through the ISM model, clarifies the relationship between related factors, When looking for ways to reduce the cost of medical logistics, it is necessary to consider the relationship between the different factors, and analyze the effects of various factors on the medical logistics cost in the view of system.

\section{References}

1. Lin Xiaoxia. Analysis and design of medical logistics distribution system, Fujian computer, 30,2(2014) 132-133.

2. Zhang Luyue. Study on the cost of drug logistics distribution, Business Culture 2,2(2014) 193.

3. Chen Jiao, Wang Dongzi. Research on drug cloud distribution model based on Logistics 4.0 , Journal of Beihua University(Social Sciences) 16,4(2015) 33-37.

4. Wei Hua. Construction of medical logistics sharing information platform, Logistics Technology 34,7 (2004) 275277.

5. Wang Yingluo. Systems engineering. Beijing:China Machine Press,(2008)220-235.

6. CHEN Senfa. The theory and method of complex system modeling. Nanjing: Southeast University Press,(2006)273292. 